Article

\title{
New Insights into the Antioxidant and Anti-Inflammatory Effects of Italian Salvia officinalis Leaf and Flower Extracts in Lipopolysaccharide and Tumor-Mediated Inflammation Models
}

\author{
Matteo Brindisi ${ }^{1}\left({ }^{\circ}\right.$, Chouaha Bouzidi $^{2}$, Luca Frattaruolo ${ }^{1} \mathbb{C}$, Monica R. Loizzo ${ }^{1}\left(\mathbb{D}\right.$, Maria Stella Cappello ${ }^{3, *}$, \\ Annabelle Dugay ${ }^{2}$, Brigitte Deguin ${ }^{2}$, Graziantonio Lauria ${ }^{1}$, Anna Rita Cappello ${ }^{1, *}$ and Rosa Tundis ${ }^{1} \mathbb{C}$ \\ 1 Department of Pharmacy, Health and Nutritional Sciences, University of Calabria, Via Pietro Bucci, \\ 87036 Arcavacata di Rende, Italy; matteo.brindisi@unical.it (M.B.); luca.frattaruolo@unical.it (L.F.); \\ monica_rosa.loizzo@unical.it (M.R.L.); graziantonio.lauria@unical.it (G.L.); rosa.tundis@unical.it (R.T.) \\ 2 UFR de Pharmacie de Paris, Université de Paris, U.M.R. n 8038, CiTCoM-(CNRS, Université de Paris), \\ F-75006 Paris, France; chouaha.bouzidi@parisdescartes.fr (C.B.); annabelle.dugay@parisdescartes.fr (A.D.); \\ brigitte.deguin@parisdescartes.fr (B.D.) \\ 3 CNR, Institute of Science of Food Production (ISPA), Prov. le Lecce-Monteroni, 73100 Lecce, Italy \\ * Correspondence: maristella.cappello@ispa.cnr.it (M.S.C.); annarita.cappello@unical.it (A.R.C.)
}

check for updates

Citation: Brindisi, M.; Bouzidi, C.; Frattaruolo, L.; Loizzo, M.R.;

Cappello, M.S.; Dugay, A.; Deguin, B.; Lauria, G.; Cappello, A.R.; Tundis, R. New Insights into the Antioxidant and Anti-Inflammatory Effects of Italian Salvia officinalis Leaf and Flower Extracts in Lipopolysaccharide and Tumor-Mediated Inflammation Models. Antioxidants 2021, 10, 311. https://doi.org/10.3390/antiox1002 0311

Academic Editor: Stanley Omaye

Received: 29 January 2021

Accepted: 17 February 2021

Published: 19 February 2021

Publisher's Note: MDPI stays neutral with regard to jurisdictional claims in published maps and institutional affiliations.

Copyright: (c) 2021 by the authors. Licensee MDPI, Basel, Switzerland. This article is an open access article distributed under the terms and conditions of the Creative Commons Attribution (CC BY) license (https:// creativecommons.org/licenses/by/ $4.0 /)$.
Abstract: This work aimed to investigate and compare the in vitro antioxidant and anti-inflammatory effects of Salvia officinalis L. (sage) from Italy, with the aim of raising its current knowledge in this field. Leaves and flowers (S1-S8), harvested in two areas of Southern Italy, were extracted with methanol as a solvent by maceration or ultrasound-assisted extraction. Sage extracts, analysed by high pressure liquid chromatography-diode-array detection-electrospray ionization-quadrupolemass spectroscopy (HPLC-DAD-ESI-Q-MS), exerted a promising antioxidant activity investigated using ferric reducing antioxidant power (FRAP), 2,2-diphenyl-1-picrylhydrazyl (DPPH), 2,2' -azinobis(3-ethylbenzothiazoline-6-sulphonic acid) (ABTS), and $\beta$-carotene bleaching tests, and elicited a significant decrease in reactive oxygen species (ROS) production in lipopolysaccharide (LPS)stimulated RAW 264.7 murine macrophages. The anti-inflammatory activity was analysed in the same in vitro model. All the extracts did not affect cell viability although they showed anti-inflammatory activity, as they induced a decrease in nitrite levels that was greater than $50 \%$, when employed at $50 \mu \mathrm{g} / \mathrm{mL}$. Furthermore, they elicited a decrease in nitrite levels, as well as a decline in proinflammatory cytokine expression. The NF- $\mathrm{B}$ transcription factor proved to be involved in the mechanisms that underlie such effects. Interestingly, sage extracts were able to interfere with the inflammatory activity induced by breast cancer cell-conditioned media (nitrite levels were significantly decreased, $p<0.05 ; p<0.01$ ), highlighting for the first time the important role of S. officinalis in controlling inflammation processes related to neoplastic progression.

Keywords: sage; HPLC-DAD-ESI-Q-MS; anti-inflammatory activity; antioxidant effects; cancer cell-conditioned media

\section{Introduction}

Salvia L. is one of the major genera in the Lamiaceae family. It includes about 900 species, many of which are used as spices or as flavouring agents in cosmetic industries [1]. Terpenoids and phenolic compounds are the most common and well-investigated classes of compounds that characterize the Salvia genus [2,3]. Other identified classes of compounds include tannins, alkaloids, fatty acids, and steroids [3]. Several Salvia species have shown interesting biological properties, including antioxidant [4,5], antimicrobial [6], anticancer [4], and anti-inflammatory effects [5,7].

Salvia officinalis L. (commonly known as sage) is a perennial, evergreen subshrub widely used in traditional medicine, native to the Mediterranean area, despite the fact that it has naturalized in many sites throughout the world. S. officinalis is one of the most 
widely appreciated plants due to its plethora of bioactive constituents that are mainly made up of terpenoids and phenolic acids [8]. A literature survey revealed that much of the phytochemical investigation in this species has focused on its essential oil. Such studies have identified various molecules, with the major constituents being camphor, 1,8-cineole, $\alpha$-thujone, borneol, $\beta$-thujone, and viridiflorol [9]. However, other polar constituents have also been isolated, including carnosol, carnosic acid, rosmarinic acid, several flavonoids, and phenolic glycosides [8]. Many studies of this Salvia species have reported anti-cancer and anti-mutagenic properties related to several cancers including colon and breast cancer, as well as its antimicrobial, antidementia, hypoglycaemic, antinociceptive, antioxidant, and anti-inflammatory properties [2]. Kolac et al. [5] investigated the antioxidant and anti-inflammatory activities of S. officinalis in a lipopolysaccharide (LPS)-induced inflammation model. Superoxide dismutase, catalase, and glutathione peroxidase activities in the inflammation group were significantly higher in the group treated with S. officinalis. The inflammation group showed increased levels of nitric oxide (NO), tumor necrosis factor- $\alpha$ (TNF- $\alpha$ ), and nuclear factor NF- $\mathrm{KB}$. S. officinalis showed promising effects on LPSinduced inflammation and oxidative stress in rats. Terpenes and polyphenols (including flavonoids) are the constituents of sage that most probably contribute to the antinociceptive and anti-inflammatory effects of this Salvia species [10]. Flavonoids isolated from S. officinalis reduced inflammation in the mouse carrageenan model and showed analgesic effects [10]. Previously, Osakabe et al. [11] showed that rosmarinic acid, one of the most abundant compounds that characterize the phytocomplex of S. officinalis), topically used inhibited epidermal inflammation.

Over the years, increasingly advanced extraction techniques have been developed and optimized which have improved the quality and specificity of extracts. However, when dealing with plants, a key role, regarding the yield and composition in phytocomplexes, is played by the conditions and/or the place and season of collection, as well as the part of plant used for extraction [8]. In this context, herein, the chemical profiles of S. officinalis extracts obtained by ultrasound-assisted extraction and maceration of leaves and flowers, collected in two areas of Southern Italy (Orsomarso and Civita) were analysed. Subsequently, their antioxidant and anti-inflammatory effects were assessed. We focused this research on oxidative stress and inflammation, two topics which have aroused increasing attention in recent years. Oxidative stress is reported as an imbalance between both free radicals and reactive oxygen species (ROS) production, and their elimination is mediated by antioxidant mechanisms. This imbalance elicits severe biomolecular and cellular damage, inducing potential effects on the whole organism. In the last decade, various studies have demonstrated that continuous oxidative stress is able to trigger the inflammatory process which, if it becomes chronic, can mediate many diseases, including cancer. Several reports support the link between the oxidative state, inflammatory process, and cancer, which is further confirmed by the anti-tumor efficacy displayed by anti-inflammatory and antioxidant therapy [12-14]. The close relationship between inflammation and neoplastic onset/progression, prompted us to assess whether S. officinalis extracts from Orsomarso and Civita were able to interfere in the inflammatory microenvironment produced by tumor cells. To this end, for the first time, we investigated the potential effects of S. officinalis extracts in reducing the inflammation related to breast cancer cell progression.

\section{Materials and Methods}

\subsection{Chemicals and Reagents}

All the solvents of analytical grade were purchased from VWR International s.r.l. (Milan, Italy). The liquid chromatography-mass spectrometry (LC-MS) quality grade methanol and acetonitrile were obtained from Carlo Erba (Val de Reuil, France). Ultrapure water $(18.2 \mathrm{M} \Omega . \mathrm{cm})$ was obtained from Elga and Purelab Classic (Veolia Water, Antony, France). Formic acid (used at $10 \mathrm{~g} / \mathrm{L}$ ) was provided from Carlo Erba (Val de Reuil, France). Standard molecules, namely rutin (purity $>99 \%$ ), carnosol (purity $>90 \%$ ), luteolin-7-glucoside (purity $>98 \%$ ), ursolic acid (purity $>98 \%$ ), rosmarinic acid (purity $>99 \%$ ), and carnosic acid 
(purity $>90 \%$ ) were purchased from Extrasynthese (Genay, France). The Folin-Ciocalteu reagent, ascorbic acid, 2,2-diphenyl-1-picrylhydrazyl (DPPH), quercetin, propyl gallate, linoleic acid, chlorogenic acid, $\beta$-carotene, dimethyl sulfoxide (DMSO), sodium carbonate, butylated hydroxytoluene (BHT), 2,2'-azino-bis (3-ethylbenzothiazoline-6-sulfonic acid) diammonium salts (ABTS), Fetal Bovine Serum (FBS), and Tween 20 were purchased from Sigma-Aldrich S.p.a. (Milan, Italy).

\subsection{Plant Materials}

S. officinalis leaves and flowers were collected in June 2018 in two localities of Southern Italy, in particular in Orsomarso $\left(39^{\circ} 48^{\prime} \mathrm{N}, 15^{\circ} 55^{\prime} \mathrm{E}, 240 \mathrm{~m}\right.$ above sea level) (voucher specimen n. CLU 26259), and in Civita (39 $50^{\prime} \mathrm{N}, 16^{\circ} 19^{\prime} \mathrm{E}, 620 \mathrm{~m}$ above sea level) (voucher specimen n. CLU 26262). Samples have been identified by Dr. NG Passalacqua, Natural History Museum of Calabria and the Botanic Garden (University of Calabria, Italy). In each locality, aerial parts were harvested in order to obtain adequate amounts for the chemical and biological analysis. Both leaves and flowers were examined to verify the absence of insect contamination and dust as well as the integrity.

\subsection{Extraction Procedure}

Fresh leaves and flowers of $S$. officinalis were subjected to two extraction procedures using methanol as a solvent: 1) Maceration ( $1 \mathrm{~L}, 3 \times 72 \mathrm{~h})$, and 2) ultrasound-assisted extraction by using the Branson 3800 ultrasonic system, series CPXH $(130 \mathrm{~W}, 40 \mathrm{kHz}$ frequency (Milan, Italy) $(150 \mathrm{~mL}, 3 \times 1 \mathrm{~h})$. In Table 1 , the extraction yields are reported.

Table 1. The qPCR primers sequences.

\begin{tabular}{cc}
\hline Primer $\mathbf{N a m e}$ & Sequence $\mathbf{( 5}^{\prime} \mathbf{-} \mathbf{3}^{\prime} \mathbf{)}$ \\
\hline TNF $\alpha \mathrm{Fw}$ & CAGGCGGTGCCTATGTCTC \\
TNF $\alpha \mathrm{Rv}$ & CGATCACCCCGAAGTTCAGTAG \\
IL-1 $\beta \mathrm{Fw}$ & GAAATGCCACCTTTTGACAGTG \\
IL-1 $\beta \mathrm{Rv}$ & TGGATGCTCTCATCAGGACAG \\
IL-6 Fw & CTGCAAGAGACTTCCATCCAG \\
IL-6 Rv & AGTGGTATAGACAGGTCTGTTGG \\
GAPDH Fw & ACCACAGTCCATGCCATCAC \\
GAPDH Rv & TCCACCACCCTGTTGCTGTA \\
\hline
\end{tabular}

\subsection{Total Phenol Content (TPC)}

The Total Phenol Content (TPC) was determined using the Folin-Ciocalteu reagent [15] Absorbance was read at $765 \mathrm{~nm}$ using a UV-Vis Jenway 6003 spectrophotometer (Milan, Italy) and TPC was expressed as mg of chlorogenic acid equivalents (CA)/g of plant materials.

\subsection{Total Flavonoid Content (TFC)}

To assess the total flavonoid content (TFC), a previously described spectrophotometric method was employed [15]. Absorbance was measured at $510 \mathrm{~nm}$ and TFC was expressed as $\mathrm{mg}$ of quercetin equivalents $(\mathrm{QE})$ /gram of plant materials.

\subsection{High Pressure Liquid Chromatography-Diode-Array Detection-Electrospray Ionization-Quadrupole-Mass Spectroscopy (HPLC-DAD-ESI-Q-MS) Compounds Profiling}

The extracts of $S$. officinalis (S1-S8) were analysed using an HPLC-DAD-MS ThermoScientific Dionex U3000 (Thermo-Dionex, Les Ulis, France) including a quaternary pump (LPG-3400 SD), a thermostat column (TCC-3000SD), a thermostat autosampler (WPS-3000TSL), and a diode array detector (DAD-3000) in line with a quadrupole mass spectrometer (Surveyor MSQ plus System, Thermo-Dionex, Les Ulis, France). The analytical column was a C18 Acclaim Polar advantage II $(3 \mu \mathrm{m}, 120 \AA, 100 \times 2.1 \mathrm{~mm}$ i.d.) (Dionex 
Bonded Silica Products, Les Ulis, France) heated to $35^{\circ} \mathrm{C}$ during the analyses. The pump flow rate was $0.5 \mathrm{~mL} / \mathrm{min}$. The injection volume was $20 \mu \mathrm{L}$.

Two chromatographic mobile phases were used. Eluent A was formic acid $(1 \%, V / V)$ in water and eluent $\mathrm{B}$ was formic acid $(1 \%, V / V)$ in acetonitrile. The binary gradient was formulated as follows: $5 \%$ eluent $B$ during 5 min then, in 10 min eluent $B$ reached $20 \%$, and in 5 min eluent $B$ reached $25 \%$, in 10 min eluent $B$ reached $30 \%$, in 10 min eluent $B$ reached $40 \%$, in 5 min eluent B reached $50 \%$, in 5 min eluent B reached $80 \%$, then stayed at $80 \%$ during 3 min before coming back to the initial conditions in $2 \mathrm{~min}$.

UV spectra were performed using a diode array detector with a wavelength scanning between 200 and $400 \mathrm{~nm}$. Detection at definite wavelengths such as 210, 254, 280, and $350 \mathrm{~nm}$, was used to record the chromatograms. The chromatographic effluent carried by a stream of nitrogen was directed into the electrospray ionization source (ESI) of the mass spectrometer (MS). The MS was operated in the positive and negative ionization modes with the following conditions: Ion spray voltage $3 \mathrm{kV}$, curtain gas $50 \mathrm{psi}$, Q energy was $70 \mathrm{~V}$, cone voltage $50 \mathrm{~V}$, desolvation temperature $500{ }^{\circ} \mathrm{C}$, and ion energy $0.8 \mathrm{~V}$. In all cases, mass spectra were acquired in the range of $100-1000$ Th. Chromeleon ${ }^{\circledR}$, version 6.8 software provided by Thermo Scientific Dionex (Les Ulis, France) was used for the treatment of the results. All the experiments were conducted successively over 3 days, in triplicates each time. Finally, compounds present in the sage extracts have been identified and quantified using a methanolic standard solution of pure compounds previously described in S. officialis such as rutin, rosmarinic acid, ursolic acid, and luteolin-7-glucoside [16,17]. Standard chromatograms recorded after the HPLC-DAD-ESI-Q-MS experiments are reported in Figure 1. For these experiments, the following solutions have been prepared: Carnosol $(0.51 \mathrm{~g} / \mathrm{L})$, luteolin-7-glucoside $(0.26 \mathrm{~g} / \mathrm{L})$, carnosic acid $(0.50 \mathrm{~g} / \mathrm{L})$, rosmarinic acid $(0.97 \mathrm{~g} / \mathrm{L})$, ursolic acid $(0.71 \mathrm{~g} / \mathrm{L})$, and rutin $(0.16 \mathrm{~g} / \mathrm{L})$. Calibration curves used a linear fitting (unweight and not forced to axis-origin) in the concentrations range of $0.008-0.4 \mathrm{~g} / \mathrm{L}$. A coefficient determination R2 $>0.99$ was used as an acceptability threshold for calibration purposes. The results were expressed as g/L. Carnosol and carnosic acid have not been evaluated as they are not stable over time as previously indicated [12]. S. officinalis extracts were dissolved in methanol before being analysed in HPLC-DAD-MS:S1 $(1.86 \mathrm{~g} / \mathrm{L}) ; \mathrm{S} 2(1.47 \mathrm{~g} / \mathrm{L})$; S3 (2.24 g/L); S4 (2.04 g/L); S5 (1.92 g/L); S6 (1.46 g/L); S7 (2.07 g/L), and S8 (2.24 g/L).

\subsection{In Vitro Antioxidant Activity}

S. officinalis extracts (S1-S8) have been investigated for their potential antioxidant effects by applying four assays namely Ferric Reducing Antioxidant Power (FRAP), ABTS, $\beta$-carotene bleaching, and DPPH tests following the procedures previously described [15].

In the ABTS test, after $12 \mathrm{~h}$ of incubation, the ABTS solution was diluted with methanol to a final absorbance of 0.70 at $734 \mathrm{~nm}$. Sequentially, $2 \mathrm{~mL}$ of the diluted ABTS solution was added to the sage extract at concentrations in the range 1-400 $\mu \mathrm{g} / \mathrm{mL}$. After $6 \mathrm{~min}$, the absorbance was read at $734 \mathrm{~nm}$. In the DPPH test, S. officinalis extracts at different concentrations $(62.5-1000 \mu \mathrm{g} / \mathrm{mL})$ were added to the DPPH solution. After $30 \mathrm{~min}$ of incubation, the absorbance was measured at $517 \mathrm{~nm}$. Ascorbic acid was selected as a positive control in both ABTS and DPPH tests. The ability to reduce iron ions of sage extracts was examined using the FRAP test. Samples were tested at the concentration of $1 \mathrm{mg} / \mathrm{mL}$ and the FRAP value was expressed as $\mu \mathrm{M} \mathrm{Fe}(\mathrm{II}) / \mathrm{g}$. The absorbance was read at $595 \mathrm{~nm}$. BHT (butylated hydroxytoluene) was used as a positive control. The potential of sage extracts to inhibit lipid peroxidation was evaluated using the $\beta$-carotene bleaching test. Samples were tested at different concentrations that ranged from 100 to $2.5 \mu \mathrm{g} / \mathrm{mL}$ and propyl gallate was used as a positive control. 


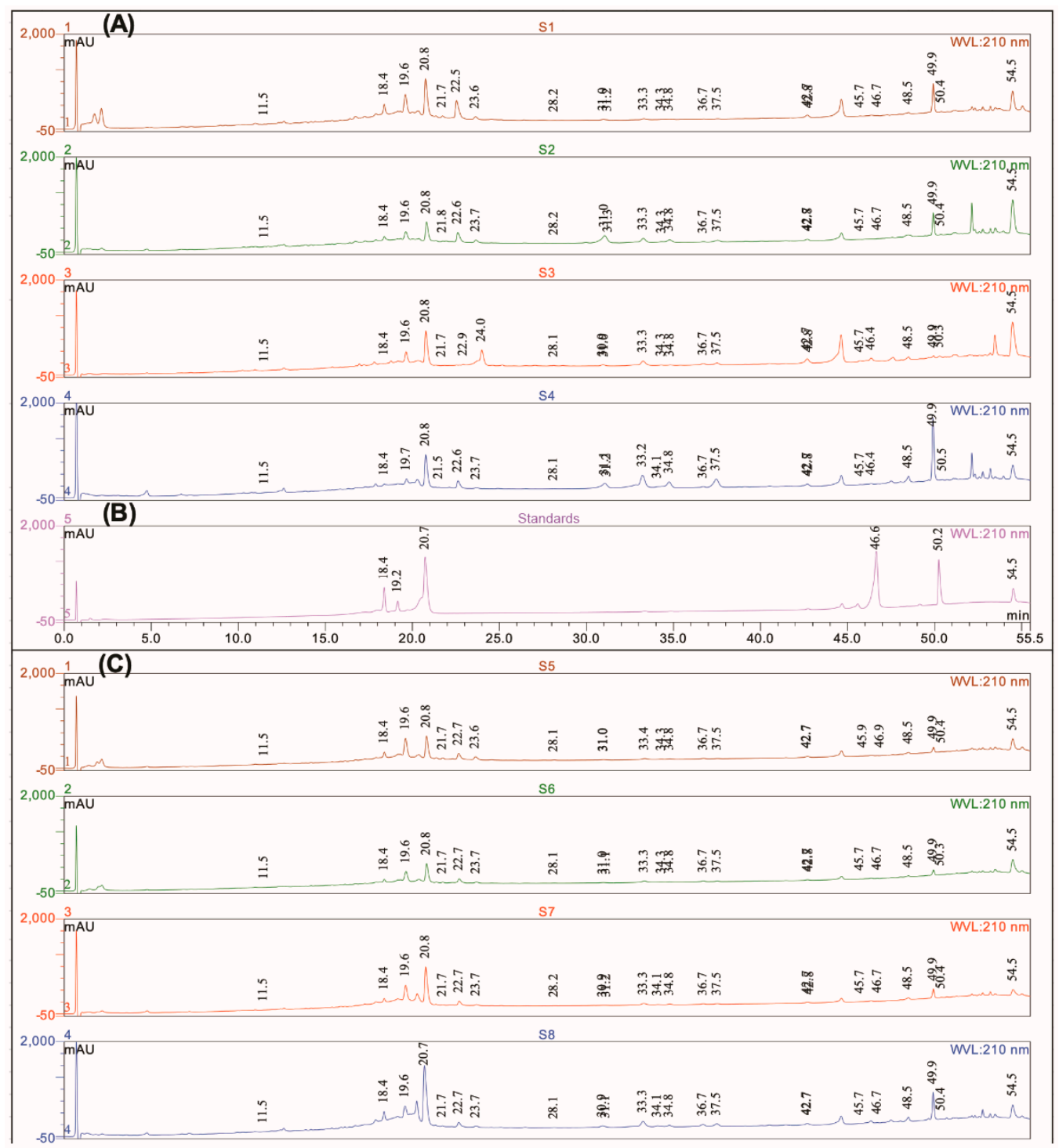

Figure 1. Compounds identification at $210 \mathrm{~nm}$ : Profiles of extracts of S. officinalis from Orsomarso: (A) S1, S2, S3, and S4. (B) The mixture of standards is obtained by diluting to one fifth of the solution initially prepared: Luteolin-7-glucoside $(0.052 \mathrm{~g} / \mathrm{L}$, retention time $(\mathrm{Rt})=18.4 \mathrm{~min})$, rosmarinic acid $(0.194 \mathrm{~g} / \mathrm{L}, \mathrm{Rt}=20.7 \mathrm{~min})$, rutin $(0.032 \mathrm{~g} / \mathrm{L}, \mathrm{Rt}=19.2 \mathrm{~min})$, carnosol (0.102 g/L, Rt = $46.6 \mathrm{~min})$, carnosic acid $(0.082 \mathrm{~g} / \mathrm{L}, \mathrm{Rt}=50.2 \mathrm{~min})$, and ursolic acid $(0.142 \mathrm{~g} / \mathrm{L}, \mathrm{Rt}=54.5 \mathrm{~min})$. Profiles of S. officinalis extracts from Civita: (C) S5, S6, S7, and S8.

\subsection{Cell Cultures}

RAW 264.7 cell line and breast cancer cells (MCF7 and MDA-MB-231) were acquired from the American Culture Collection (ATCC, Manassas, VA, USA). RAW 264.7 cells were grown in DMEM (Sigma-Aldrich, St. Louis, MO, USA) supplemented with $2 \mathrm{mM}$ L-glutamine (Gibco, Life Technologies, Waltham, MA, USA), 10\% Fetal Bovine Serum (FBS, Sigma-Aldrich, St. Louis, MO, USA), and 1\% penicillin/streptomycin (Gibco, Life Technologies, Waltham, MA, USA), whereas MCF7 and MDA-MB-231 were cultured in DMEM/F12 (Sigma-Aldrich, St. Louis, MO, USA) supplemented with $1 \%$ penicillin/streptomycin (Gibco, Life Technologies, Waltham, MA, USA) and 10\% FBS, as reported previously [18]. All the cell lines were maintained at $37^{\circ} \mathrm{C}$ in a humidified atmosphere $\left(5 \% \mathrm{CO}_{2}\right)$.

\subsection{Reactive Oxygen Species (ROS) Assessment}

ROS were quantified using the chloromethyl derivative of 2',7'-dichlorodihydrofluorescein diacetate $\left(\mathrm{CM}-\mathrm{H}_{2} \mathrm{DCFDA}\right.$, Thermo Fisher Scientific, Waltham, MA, USA), as previously 
described [19,20]. Briefly, 2x10 RAW 264.7 cells/well were seeded in 6-well plates and simultaneously treated for $1 \mathrm{~h}$ with extracts, at their $\mathrm{IC}_{50}$ values, and LPS $(1 \mu \mathrm{g} / \mathrm{mL})$. Then, the treated cells were rinsed with PBS, harvested, resuspended in $5 \mu \mathrm{M} \mathrm{CM}-\mathrm{H}_{2} \mathrm{DCFDA}$, a fluorescent probe used as an indicator for ROS, in PBS and incubated at $37^{\circ} \mathrm{C}$, for $45 \mathrm{~min}$. Subsequently, the stained cells were harvested by centrifugation and maintained in a fresh medium. Lastly, each fluorescence sample was quantified by fluorimetry (Synergy H1 microplate reader, BioTek, Winooski, VT, USA), and its intensity was normalized by a viable cell number (automated cell counter, TC20, Bio-Rad, Hercules, CA, USA).

\subsection{NO Production in LPS-Stimulated RAW 264.7 Cells}

Stable oxidized products of NO in cell culture media were assessed by the Griess reagent, as already reported [21,22]. The $2 \times 10^{5}$ RAW 264.7 cells/well were seeded in 24-well plates and cultured overnight, in the complete medium. Then, the cells were treated for $24 \mathrm{~h}$ with $1 \mu \mathrm{g} / \mathrm{mL}$ LPS and extracts, at increasing concentrations. DMSO (Sigma-Aldrich, St. Louis, MO, USA) was used as a control. Next, a cell culture supernatant share $(100 \mu \mathrm{L})$ was mixed with an equal volume of the Griess reagent in a 96-well plate and subjected to spectrophotometric analysis at $550 \mathrm{~nm}$ using a microplate reader (Synergy $\mathrm{H} 1$ microplate reader, BioTek, Winooski, VT, USA).

\subsection{Cell Viability Assay}

Cell viability was assessed using the 3-(4,5-Dimethyl-2-thiazolyl)-2,5-diphenyl-2Htetrazolium bromide (MTT, Sigma-Aldrich, St. Louis, MO, USA) assay, as previously described [23,24]. In brief, RAW 264.7 cells were exposed to increasing concentrations of each extract for $24 \mathrm{~h}$. Next, the MTT solution was put into each well (to a concentration of $0.5 \mathrm{mg} / \mathrm{mL}$ ) and plates were maintained for $2 \mathrm{~h}$ at $37^{\circ} \mathrm{C}$. Then, the formazan crystals formed in each well were solubilized in DMSO and spectrophotometrically quantified at $570 \mathrm{~nm}$, using a microplate reader.

\subsection{Immuno-Fluorescence Monitoring Nuclear Factor Kappa B (NF-kB) Translocation}

Murine macrophages were spread on coverslips in 6-well plates at $1 \times 10^{5}$ cells/well of density, and grown in a complete medium, overnight. Then, the cells were exposed for $1 \mathrm{~h}$ to $1 \mu \mathrm{g} / \mathrm{mL}$ LPS and extracts, at their $\mathrm{IC}_{50}$. Subsequently, cells were fixed for 20 min with methanol at $-20{ }^{\circ} \mathrm{C}$, rinsed three times with a Tris-buffered saline (TBS, SigmaAldrich, St. Louis, MO, USA) for $5 \mathrm{~min}$, and blocked with $5 \%$ bovine serum albumin (BSA, Sigma-Aldrich, St. Louis, MO, USA) in TBS at $37^{\circ} \mathrm{C}$, for $40 \mathrm{~min}$. After incubation at $37^{\circ} \mathrm{C}$, for $40 \mathrm{~min}$, with the anti-NF- $\mathrm{kB}$ p65 monoclonal antibody (Santa Cruz, Biotechnology, Dallas, TX, USA), as previously indicated $[19,25]$, cells were rinsed three times for $5 \mathrm{~min}$ with TBS, to discard the excess of primary antibody and incubated at $37^{\circ} \mathrm{C}$, for $40 \mathrm{~min}$, in anti-mouse IgG-TRITC (Thermo Fisher Scientific, Waltham, MA, USA). Finally, they were washed with TBS three times for $5 \mathrm{~min}$. The $20 \times$ magnification images were acquired on an Olympus BX41 microscope with the CSV1.14 software. The image acquisition was performed using a CAMXC-30.

\subsection{Quantitative PCR Analysis}

RAW 264.7 cells were grown in $10 \mathrm{~cm}$ dishes to $70-80 \%$ confluence and for $6 \mathrm{~h}$ were treated with DMSO, with $1 \mu \mathrm{g} / \mathrm{mL}$ LPS alone or in the presence of extracts at their $\mathrm{IC}_{50}$ values. The TRIZOL reagent (Sigma-Aldrich, St. Louis, MO, USA) was used to extract total cellular RNA, according to the manufacturer's instructions. RNA purity and integrity were verified by both spectroscopical analysis and gel electrophoresis. The synthesis of complementary DNA (cDNA) was obtained, via reverse transcription. The gene expression analyses of interleukin 1 beta (IL-1 $\beta$ ), tumor necrosis factor alpha (TNF $\alpha$ ), and interleukin 6 (IL-6) were achieved by the Quant Studio7 Flex Real-Time PCR System platform (Life Technologies, Waltham, MA, USA) using the SYBR Green Universal PCR Master Mix (Roche, Monza, MB, Italy), as previously described [12]. Experiments were 
performed in triplicates and expression levels of the studied genes were normalized onto the Glyceraldehyde 3-phosphate dehydrogenase (GAPDH) mRNA levels. Relative mRNA levels were calculated using the $\Delta \Delta \mathrm{Ct}$ method and comparing it with the control group. In Table 1, the primers utilized are grouped here.

\subsection{Statistical Analysis}

Experiments were performed in triplicates and data are expressed as the means \pm standard deviation (SD). The concentration giving $50 \%$ inhibition $\left(\mathrm{IC}_{50}\right)$ was calculated by nonlinear regression using the GraphPad Prism version 8.0 (GraphPad Software, San Diego, CA, USA). ANOVA followed by Dunnett's test was applied to evaluate the differences between data and positive control results in biological assays. Tukey's test was used to determine any significant difference between all the treatments at different levels. The Relative Antioxidant Capacity Index (RACI) was used to establish the antioxidant potential [26].

\section{Results and Discussion}

\subsection{Chemical Profile}

Considering the healthy properties of sage, the choice of efficient extraction procedures is drawing great attention and solvent extraction is the most used procedure.

Herein, we have extracted the fresh leaves and flowers of $S$. officinalis collected in two localities of Calabria (Southern Italy) by maceration and ultrasound-assisted extraction by using methanol as a solvent in both extraction procedures. Table 2 reports the extraction yield (\%). The analysis of the results evidenced that maceration was more effective $(9.3-7.8 \%)$ than ultrasound-assisted extraction (8.4-3.8\%) using the same solvent.

Table 2. Extraction procedures and yield (\%) of S. officinalis extracts (S1-S8).

\begin{tabular}{ccccc}
\hline S. officinalis & & Part & Extraction Procedure & Yield (\%) $^{\text {a }}$ \\
\hline Orsomarso & S1 & Leaves & Maceration & 7.8 \\
& S2 & Leaves & Ultrasound-assisted extraction & 6.2 \\
& S3 & Flowers & Maceration & 8.3 \\
& S4 & Flowers & Ultrasound-assisted extraction & 3.8 \\
\hline Civita & S5 & Leaves & Maceration & 9.3 \\
& S6 & Leaves & Ultrasound-assisted extraction & 8.4 \\
& S7 & Flowers & Maceration & 8.9 \\
& S8 & Flowers & Ultrasound-assisted extraction & 5.2 \\
\hline
\end{tabular}

${ }^{a}$ Expressed as [(g dried extract/g plant materials) $\times 100$.

The phytochemical composition of S. officinalis extracts was determined using the HPLC-DAD-ESI-Q-MS mass spectrometric method. The identification of carnosic acid, rosmarinic acid, carnosol, luteolin-7-glucoside, and ursolic acid were confirmed using authentic standards (Figure 1B). Calibration curves used a linear fitting in the concentrations range of $0.008-0.4 \mathrm{~g} / \mathrm{L}$. A coefficient determination $\mathrm{R}^{2}>0.99$ was used as an acceptability threshold for calibration purposes. The other S. officinalis constituents were identified based on retention time (Rt), wavelengths of maximum absorption in the UVVIS region, and molecular weight $\left(m / z\right.$ ion $[\mathrm{M}+\mathrm{H}]^{+}$and $\left.[\mathrm{M}-\mathrm{H}]^{-}\right)$, in comparison to the spectral data concerning the phytochemical profile of $S$. officinalis previously published [16,17,27-29]. Chromatograms allowed the putative annotation of 22 compounds as reported in Figure 1A,C, and in Table 3. 
Table 3. Retention time, wavelengths of maximum absorption in the ultraviolet (UV)-visible (VIS) region, mass spectra data, and compounds identification in S. officinalis.

\begin{tabular}{|c|c|c|c|c|c|c|}
\hline Peak & $\begin{array}{c}\text { Rt } \\
(\mathrm{min})\end{array}$ & $\mathrm{UV} \lambda(\mathrm{nm})$ & $\begin{array}{c}\text { Molecular ion } \\
{[\mathbf{M}-\mathbf{H}]^{-}(\mathrm{m} / \mathrm{z})}\end{array}$ & $\begin{array}{l}\text { Molecular Ion } \\
{[\mathrm{M}+\mathrm{H}]^{+}(m / z)}\end{array}$ & Identification & Ref \\
\hline 1 & 11.5 & $220 / 240 / 295 / 325$ & 179 & & Caffeic acid & [2] \\
\hline 2 & 18.4 & $205 / 253 / 270 / 350$ & 447 & 449 & Luteolin-7-glucoside ${ }^{2}$ & [2] \\
\hline 3 & 19.6 & $208 / 253 / 270 / 345$ & 461 & & Luteolin-O-glucuronide & [2] \\
\hline 4 & 20.8 & $220 / 251 / 290 / 330$ & 359 & 361 & Rosmarinic acid (cis,trans) $^{2}$ & [1] \\
\hline 5 & 21.5 & $250 / 290 / 330$ & 445 & & Apigenin-O-glucuronide & [2] \\
\hline 6 & 22.6 & $290 / 323$ & 555 & 557 & Salvianolic acid $\mathrm{K}$ & {$[3,4]$} \\
\hline 7 & 28.2 & $263 / 274 / 360$ & 315 & & Nepetin & [2] \\
\hline 8 & 31.0 & $286 / 340$ & 345 & 347 & Rosmanol isomer $^{1}$ & {$[1,2]$} \\
\hline 9 & 31.2 & $253 / 240 / 350$ & 285 & & Luteolin & [2] \\
\hline 10 & 33.3 & $286 / 340$ & 345 & 347 & Rosmanol isomer ${ }^{1}$ & {$[1,2]$} \\
\hline 11 & 34.3 & $220 / 270 / 340$ & 299 & & Hispidulin & [2] \\
\hline 12 & 34.8 & $286 / 340$ & 345 & 347 & Rosmanol isomer $^{1}$ & {$[1,2]$} \\
\hline 13 & 36.3 & $279 / 340$ & 313 & & Cirsimaritin & [2] \\
\hline 14 & 37.5 & $250 / 300 / 400$ & 269 & & Apigenin & [2] \\
\hline 15 & 42.6 & $265 / 331$ & 383 & & Genkwanin & [2] \\
\hline 16 & 42.8 & $205 / 290$ & 359 & 361 & 7-O-methylrosmanol & [6] \\
\hline 17 & 45.7 & $205 / 250 / 305$ & 342 & & Rosmadial & [2] \\
\hline 18 & 46.7 & $205 / 286$ & 329 & 331 & Carnosol $^{2}$ & [1] \\
\hline 19 & 48.5 & $204 / 260 / 280 / 330$ & 315 & 317 & Pedalitin & [5] \\
\hline 20 & 49.9 & $205 / 230 / 285$ & 345 & & 12-O-methylcarnosic acid & [2] \\
\hline 21 & 50.4 & $204 / 235 / 287$ & 331 & & Carnosic acid ${ }^{2}$ & [2] \\
\hline 22 & 54.5 & & & 457 & Triterpenic acids (Ursolic acid) ${ }^{2}$ & [2] \\
\hline
\end{tabular}

\footnotetext{
${ }^{1}$ Rosmanol, epirosmanol, epiisorosmanol, or/and isorosmanol. ${ }^{2}$ Identification confirmed using commercial pure compounds.
}

A very good similarity between the chromatograms is to be noted. Rosmarinic acid $(\mathrm{Rt}=20.8 \mathrm{~min})$, carnosic acid $(\mathrm{Rt}=50.4 \mathrm{~min})$, ursolic acid (or isomers [12]), $\mathrm{Rt}=54.5 \mathrm{~min})$, and luteolin-7-glucoside are identified in all the flower and leaf extracts. However, some differences or characteristics can be shown.

Luteolin-7-glucoside is present in all the extracts with a small area and not detected in the S3 extract. In the leaves or flowers, triterpenic acids are the most abundant compounds dosed, then rosmarinic acid, and finally luteolin-7-glucoside is the minority dosed compound. Luteolin-7-glucoside, rosmarinic acid, and triterpenic acids quantification is reported in Table 4.

Table 4. Luteolin-7-glucoside, rosmarinic acid, and triterpenic acids quantification in sage extracts by HPLC-DAD-Q-MS.

\begin{tabular}{|c|c|c|c|c|c|c|}
\hline & \multicolumn{2}{|c|}{$\begin{array}{l}\text { Luteolin-7-Glucoside } \\
\quad(\mathrm{Rt}=18.4 \mathrm{~min})\end{array}$} & \multicolumn{2}{|c|}{$\begin{array}{l}\text { Rosmarinic Acid } \\
(\mathrm{Rt}=20.8 \mathrm{~min})\end{array}$} & \multicolumn{2}{|c|}{$\begin{array}{l}\text { Triterpene Acids } \\
\text { (Rt = 54.5 } \mathrm{min})\end{array}$} \\
\hline & $(*)$ & $(\%)^{* *}$ & $(*)$ & $(\%)^{* *}$ & $(*)$ & $(\%)^{* *}$ \\
\hline \multicolumn{7}{|c|}{ Orsomarso } \\
\hline S1 & $0.0160 \pm 0.0049$ & 0.86 & $0.0848 \pm 0.0128$ & 4.56 & $0.2166 \pm 0.0275$ & 11.65 \\
\hline S2 & $0.0088 \pm 0.0014$ & 0.60 & $0.0514 \pm 0.0093$ & 3.50 & $0.3932 \pm 0.0539$ & 25.75 \\
\hline S3 & 0 & 0 & $0.0915 \pm 0.0193$ & 4.08 & $0.4851 \pm 0.0511$ & 21.66 \\
\hline S4 & $0.0024 \pm 0.0005$ & 0.12 & $0.1018 \pm 0.0144$ & 4.99 & $0.1574 \pm 0.0017$ & 7.72 \\
\hline \multicolumn{7}{|c|}{ Civita } \\
\hline S5 & $0.0119 \pm 0.0001$ & 0.60 & $0.0654 \pm 0.0077$ & 3.30 & $0.1249 \pm 0.0043$ & 6.31 \\
\hline S6 & $0.0054 \pm 0.0007$ & 0.37 & $0.0559 \pm 0.0005$ & 3.83 & $0.1655 \pm 0.0109$ & 11.34 \\
\hline S7 & $0.0077 \pm 0.0011$ & 0.37 & $0.1127 \pm 0.0106$ & 5.44 & $0.0756 \pm 0.0054$ & 3.65 \\
\hline S8 & $0.0160 \pm 0.0048$ & 0.71 & $0.1750 \pm 0.0440$ & 7.81 & $0.1425 \pm 0.0232$ & 6.36 \\
\hline
\end{tabular}

$\left({ }^{*}\right)$ Results are expressed as means values $(\mathrm{g} / \mathrm{L}) \pm$ standard deviation $(n=6) ;\left({ }^{* *}\right) \%$ compound quantity injected versus extract quantity injected $(g / g)$. 
The concentration of the selected compounds varied according to the extraction method with significant differences. Except for S. officinalis from Civita, methanolic maceration is more favourable for the extraction of luteolin-7-glucoside and rosmarinic acid from the leaves. For the extraction of triterpenic acids such as ursolic acid [12], a more efficient extraction was obtained using the ultrasound technique.

The ultrasound-assisted extraction was more successful than the classical maceration in extracting luteolin-7-glucoside and rosmarinic acid of the flowers. The same trend is observed for triterpene acids of the flowers from Civita.

\subsection{Antioxidant Effects}

Oxidative metabolism is indispensable for the cells survival. A side effect of this is the production of reactive oxygen species (ROS), which can induce oxidative changes.

When there is an excess of free radicals, ROS can overwhelm protective enzymes and cause destructive and lethal cellular effects by oxidizing DNA, lipids, and proteins. Oxidative stress originates from an imbalance in the antioxidant status.

Among the endogenous defences are enzymes such as superoxide dismutase, glutathione peroxidase, and catalase. In addition to these defences, the consumption of dietary antioxidants is very important. The antioxidant activity cannot be evaluated reasonably by one antioxidant assay without due regard to the several variables that influence the results. Different tests may be required to assess such antioxidant effects. For these reasons, herein sage extracts were analysed using four assays such as FRAP, ABTS, $\beta$-carotene bleaching, and DPPH tests. Results ( $\mathrm{IC}_{50}$ values) are reported in Table 5.

Table 5. Total phenols content (TPC), total flavonoids content (TFC), and antioxidant effects of S. officinalis S1-S8 extracts.

\begin{tabular}{|c|c|c|c|c|c|c|c|}
\hline \multirow[t]{2}{*}{ Sample } & \multirow[t]{2}{*}{ TPC $^{1}$} & \multirow[t]{2}{*}{$\mathrm{TFC}^{2}$} & \multirow[t]{2}{*}{ DPPH Test ${ }^{3}$} & \multirow[t]{2}{*}{ ABTS Test ${ }^{3}$} & \multicolumn{2}{|c|}{$\beta$-Carotene Bleaching Test ${ }^{3}$} & \multirow[t]{2}{*}{ FRAP Test $^{4}$} \\
\hline & & & & & $30 \mathrm{~min}$ & $60 \mathrm{~min}$ & \\
\hline S1 & $40.3 \pm 1.5^{b}$ & $25.2 \pm 1.4^{b}$ & $12.4 \pm 1.2^{* * * *}$ & $0.9 \pm 0.08$ & $7.1 \pm 0.7^{* * * *}$ & $11.6 \pm 1.2^{* * * *}$ & $98.4 \pm 6.3$ \\
\hline S2 & $18.8 \pm 1.0^{\mathrm{f}}$ & $12.6 \pm 0.6^{f}$ & $10.4 \pm 1.0^{* * * *}$ & $0.9 \pm 0.04$ & $3.5 \pm 0.3$ & $3.2 \pm 0.3$ & $65.2 \pm 4.2$ \\
\hline S3 & $41.9 \pm 1.6^{\mathrm{a}}$ & $15.4 \pm 0.9^{\mathrm{d}}$ & $9.8 \pm 0.9^{* * * *}$ & $0.9 \pm 0.09$ & $2.9 \pm 0.2$ & $2.5 \pm 0.2$ & $95.5 \pm 6.1$ \\
\hline $\mathrm{S} 4$ & $25.7 \pm 0.8^{\mathrm{e}}$ & $14.5 \pm 0.8^{\mathrm{e}}$ & $10.8 \pm 1.3^{* * * *}$ & $1.1 \pm 0.1$ & $3.8 \pm 0.4$ & $4.3 \pm 0.4^{* *}$ & $72.1 \pm 4.4$ \\
\hline S5 & $39.8 \pm 1.5^{\mathrm{c}}$ & $17.7 \pm 0.9^{\mathrm{c}}$ & $10.3 \pm 1.0^{* * * *}$ & $1.9 \pm 0.2$ & $5.1 \pm 0.5^{* *}$ & $4.8 \pm 0.4^{* *}$ & $69.1 \pm 4.4$ \\
\hline S6 & $35.3 \pm 1.1^{\mathrm{d}}$ & $14.9 \pm 1.1^{\mathrm{e}}$ & $11.8 \pm 1.1^{* * * *}$ & $1.1 \pm 0.1$ & $2.0 \pm 0.2$ & $2.5 \pm 0.2$ & $84.5 \pm 5.1$ \\
\hline S7 & $41.6 \pm 1.2^{\mathrm{a}}$ & $26.6 \pm 0.7^{\mathrm{a}}$ & $9.8 \pm 0.9^{* * * *}$ & $1.2 \pm 0.1$ & $4.0 \pm 0.4^{*}$ & $4.9 \pm 0.5^{* *}$ & $87.1 \pm 6.3$ \\
\hline S8 & $18.7 \pm 0.1^{\mathrm{f}}$ & $12.4 \pm 0.4^{\mathrm{f}}$ & $11.8 \pm 1.1^{* * * *}$ & $0.9 \pm 0.09$ & $7.0 \pm 0.7^{* * * *}$ & $7.1 \pm 0.7^{* * * *}$ & $94.4 \pm 6.3$ \\
\hline \multicolumn{8}{|c|}{ Positive control } \\
\hline $\begin{array}{c}\text { Ascorbic } \\
\text { acid }\end{array}$ & & & $5.0 \pm 0.8$ & $1.7 \pm 0.06$ & & & \\
\hline $\begin{array}{l}\text { Propyl } \\
\text { gallate }\end{array}$ & & & & & $1.0 \pm 0.03$ & $0.09 \pm 0.004$ & \\
\hline $\mathrm{BHT}$ & & & & & & & $63.2 \pm 4.3$ \\
\hline
\end{tabular}

${ }^{1}$ Total phenols content (TPC): Mg chlorogenic acid (CA) equivalents/g plant materials; ${ }^{2}$ Total flavonoids content (TFC): Mg quercetin (QE) equivalents/g plant materials; ${ }^{3} \mathrm{IC}_{50}(\mu \mathrm{g} / \mathrm{mL})^{4} \mu \mathrm{M}$ Fe (II) $/ \mathrm{g}$ (at a concentration of $1 \mathrm{mg} / \mathrm{mL}$. Data are expressed as the mean \pm standard deviation $(n=3)$. Means in the same column with different small letters differ significantly $(p<0.05)$. Differences within and between groups were evaluated by one-way ANOVA followed by a multi-comparison Dunnett's test $(\alpha=0.05)$ : ${ }^{* * * *} p<0.0001,{ }^{* *} p<0.01,{ }^{*} p<0.1$, compared with the positive controls in the biological assay, whereas multi-comparison Tukey's test was applied for an evaluation of the phytochemical content $(p<0.05)$.

In the DPPH assay, the most interesting results were observed with samples S3 and S7, namely the extracts obtained by maceration of the flowers from Orsomarso and Civita, respectively, with the $\mathrm{IC}_{50}$ value of $9.8 \mu \mathrm{g} / \mathrm{mL}$. Both samples are characterized by the highest TPC (41.9 and $41.6 \mathrm{mg} / \mathrm{g}$ plant materials for S3 and S7, respectively). Interesting results were also obtained with S2 and S5 with $\mathrm{IC}_{50}$ values of 10.4 and $10.3 \mu \mathrm{g} / \mathrm{mL}$, respectively.

In the ABTS test, except for S5, all the sage extracts $\left(\mathrm{IC}_{50}\right.$ in the range $0.9-1.2 \mu \mathrm{g} / \mathrm{mL}$ ) are more active than ascorbic acid ( $\mathrm{IC}_{50}$ of $1.7 \mu \mathrm{g} / \mathrm{mL}$ ), used as a positive control. 
The extract with the greatest ability to protect the oxidation of $\beta$-carotene is S6 with $\mathrm{IC}_{50}$ of 2.0 and $2.5 \mu \mathrm{g} / \mathrm{mL}$ after 30 and $60 \mathrm{~min}$ of incubation, respectively. Comparable values were obtained with S3 with $\mathrm{IC}_{50}$ values of 2.9 and $2.5 \mu \mathrm{g} / \mathrm{mL}$ after 30 and $60 \mathrm{~min}$ of incubation, respectively.

In the FRAP test, sage extracts are more active than the positive control BHT. The most promising are the extracts S1, S3, and S8 with values of 98.4, 95.5, and $94.4 \mu \mathrm{M} \mathrm{Fe}(\mathrm{II}) / \mathrm{g}$.

In Table 5, the total phenols content (TPC) and total flavonoids content (TFC) are also reported. Generally, extracts obtained by maceration exhibited the highest TPC and TFC than samples obtained by ultrasound-assisted extraction. The highest content of phenols was found in samples S3 and S7 with values of 41.9 and $41.6 \mathrm{mg}$ CA equivalents/g plant materials, respectively. S7 and S1 were the richest extracts in flavonoids with values of 26.6 and $25.2 \mathrm{mg}$ QE equivalents/g plant materials, respectively.

The statistical approach relative antioxidant capacity index (RACI) was used to establish the antioxidant rank of Salvia extracts (Figure 2). Sample S3 showed the highest activity followed by the S2 and S6 extracts.

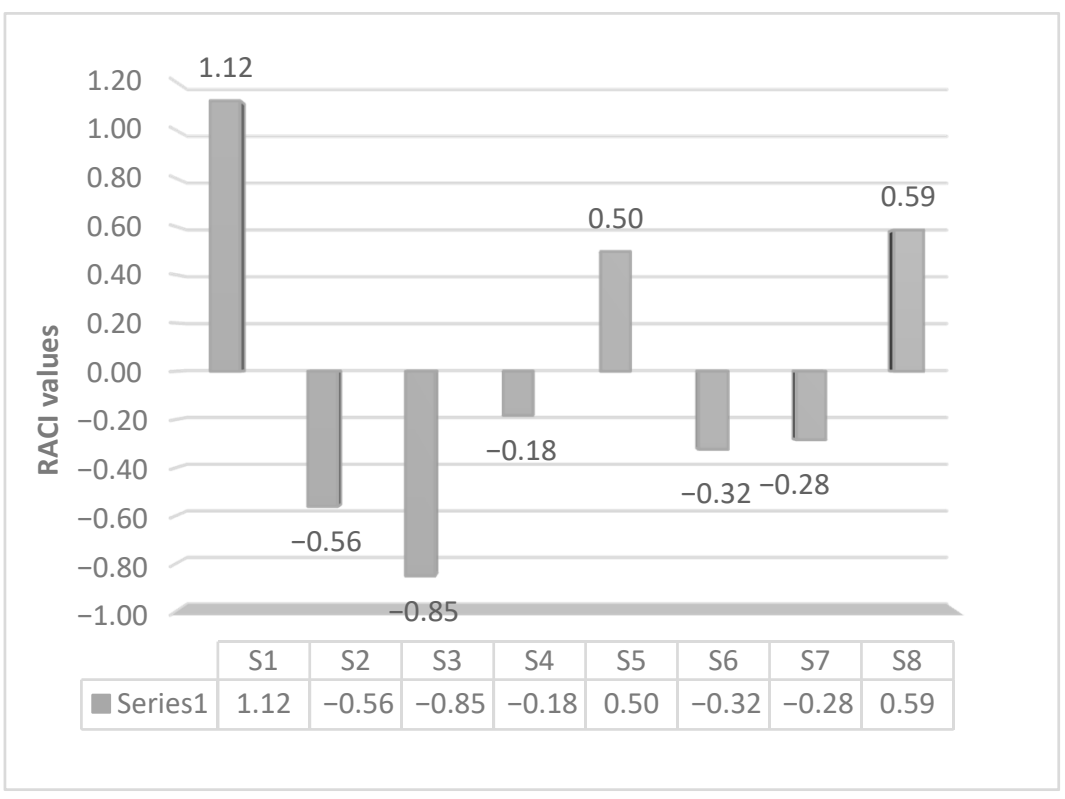

Figure 2. Relative antioxidant capacity index (RACI) values of sage extracts (S1-S8).

Several works have shown S. officinalis to be one of the main sources of potent antioxidants [30]. The antioxidant effects of $S$. officinalis were mainly related to the presence of carnosic acid and rosmarinic acid. Rosmarinic acid showed strong antioxidant effects in several in vitro and in vivo studies [31].

Rosmarinic acid was demonstrated to suppress ROS generation and inhibit lipids peroxidation. Moreover, it showed free radicals scavenging effects in hepatic stellate cells as a result of its antioxidant activity by increasing glutathione synthesis and by participating in the NF- $\mathrm{KB}$-dependent inhibition of matrix metalloproteinase-2 activity. This compound increased the catalase, glutathione peroxidase, and superoxide dismutase activities [31]. However, other works on S. officinalis have reported the presence of numerous diterpenoids, phenolic acids, and flavonoids that demonstrated a remarkable antioxidant activity including sage constituents identified in our samples such as carnosol, carnosic acid, luteolin, caffeic acid, 7-O-methylrosmanol, apigenin, rosmadial, pedalitin, 12-O-methylcarnosic acid, apigenin-O-glucuronide, luteolin-7-glucoside, luteolin-O-glucuronide, nepetin, hispidulin, cirsimaritin, and genkwanin [32].

Carnosic acid and carnosol were able to protect the lipids from oxidation. Loussouarn et al. [33] showed that upon the ROS oxidation of lipids, carnosic acid was consumed and oxidized into several compounds that include carnosol, whereas carnosol 
resisted. This suggested that carnosic acid is a chemical quencher of ROS. Carnosol occurs in the lipid oxidation process. Under oxidative conditions that did not include the ROS generation, contrary to carnosic acid, carnosol inhibited lipid peroxidation. [33].

\subsection{S. officinalis Extracts Reduce ROS Levels}

Oxidative stress exerts a crucial role in the initiation and progression of various pathologies including cancer. Of all the species produced under such conditions, ROS are the most abundant [34]. The ROS intracellular concentration, as well as the balance between ROS and endogenous antioxidant compounds can induce cellular impairment, damaging proteins, lipids, RNA, and DNA [35].

Natural antioxidants have been reported to display antioxidant activity, reducing intracellular ROS production, thus preventing damage caused by high oxidative stress conditions [36]. In this context, several research groups have proved that $S$. officinalis extracts endowed with a powerful antioxidant activity manage to prevent many of the effects mediated by oxidative stress, such as DNA damage $[37,38]$. This effect was promptly ascribed to the massive presence in phytocomplexes of compounds with a remarkable antioxidant activity. These literature data, as well as the promising antioxidant activity exhibited by leaves and flowers of Salvia officinalis extracts in our different antioxidant in vitro assays, prompted us to evaluate whether these extracts were able to manifest antioxidant activities in the cell. In detail, based on the close connection between oxidative stress and inflammation [39], we evaluated intracellular ROS levels, in LPS-stimulated RAW 264.7 murine macrophage-like cells widely used as an in vitro model to assess the inflammatory process. This system allowed us to highlight, for the first time, that Salvia officinalis extracts were able to reduce oxidative stress induced by an inflammatory stimulus. Indeed, murine macrophage-like cells stimulated with LPS displayed increased intracellular levels of radical oxygen species (Figure 3). Instead, after treatment with Salvia officinalis extract, they exhibited significant decreases in ROS production, with the exception of those treated with S3 and S8 (Figure 3). This confirms the good antioxidant activity exhibited by the extracts, even at the cellular level, in the above in vitro antioxidant assays, highlighting the ability of $S$. officinalis species to reduce the oxidative stress induced by an inflammatory process.

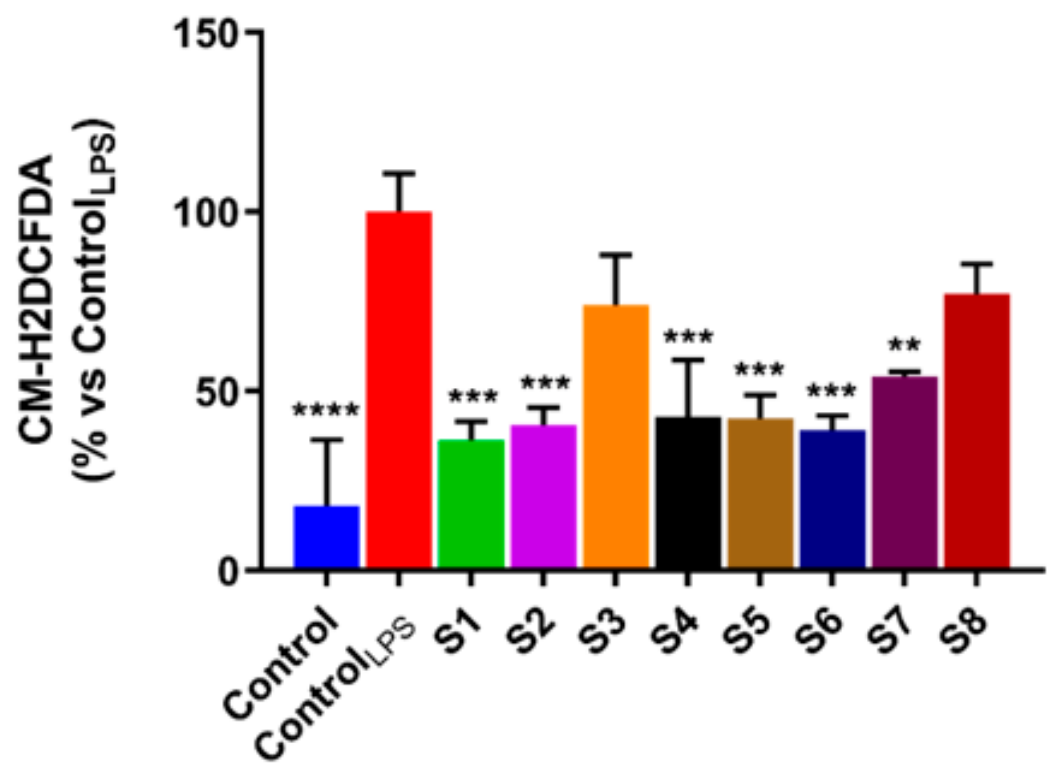

Figure 3. Salvia officinalis extracts decrease the reactive oxygen species (ROS) in lipopolysaccharide (LPS)-stimulated RAW 264.7 cells. Cells were exposed to S. officinalis extracts (S1-S8), for 24 h; ROS intracellular levels were assessed, using the CM-H2DCFDA dye, as reported in Materials and Methods. Values are the mean $\pm \mathrm{SD}$ of three independent experiments, each one performed in triplicate. $p$-values were calculated vs. control $_{\mathrm{LPS}} ;^{* *} p<0.01$; $^{* * *} p<0.001{ }^{* * * *} p<0.0001$. 


\subsection{S. officinalis Extracts Reduce NO Production Inhibiting NF- $\kappa B$}

It is known that different inflammatory stimuli, such as LPS, can trigger several inflammatory diseases by regulating nitric oxide (NO) levels [39]. Indeed, in LPS-stimulated cells, NO exerts a pivotal role in the inflammatory process. Based thereon, and given the many compounds endowed with potential anti-inflammatory activity detected in the Salvia officinalis leaf and flower extracts tested, we next evaluated their ability to reduce the NO release (Figure 4A,B).

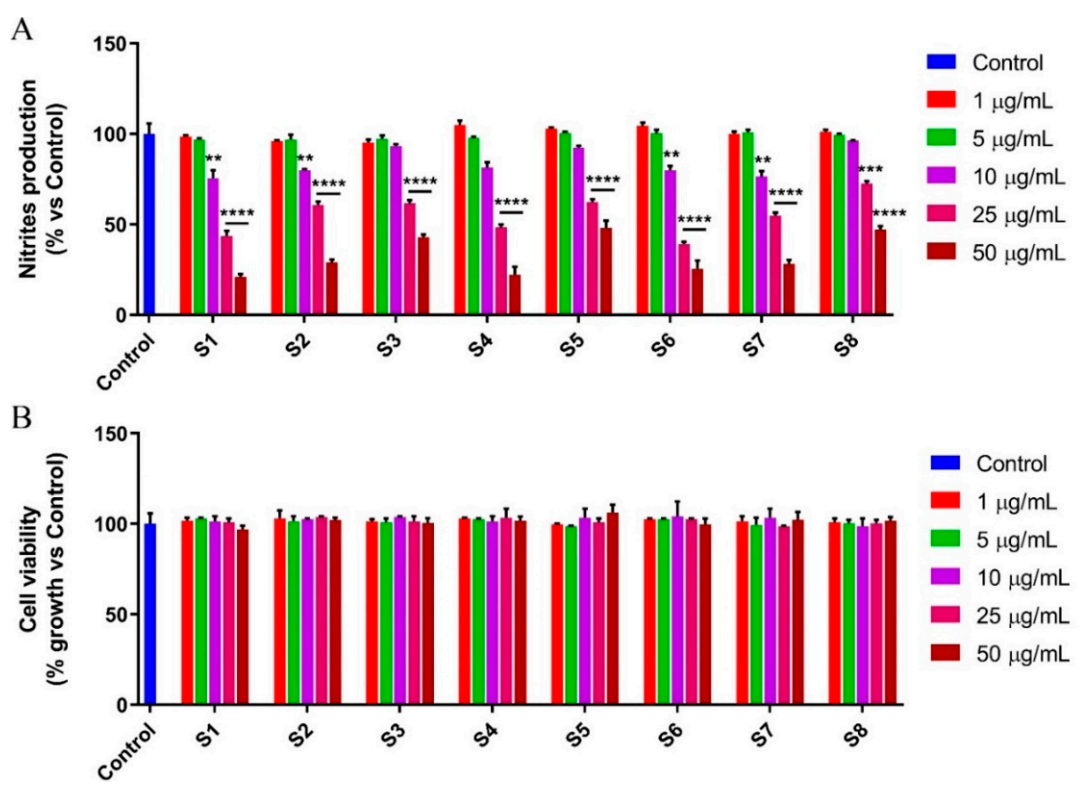

Figure 4. S1-S8 extracts significantly reduce nitric oxide (NO) production. Nitrites production (A) and cell viability (B) were assessed by the Griess and MTT assays, respectively, after $24 \mathrm{~h}$ of treatment of the LPS-stimulated RAW 264.7 cell line with sage extracts, at increasing concentrations (from 1 to $50 \mu \mathrm{g} / \mathrm{mL}$ ). The results of the Griess assay are expressed as a percentage of nitrites production vs. control, while the MTT assay results are indicated as a percentage of cell viability vs. control. Values are the mean $\pm \mathrm{SD}$ of three independent experiments, each one performed in triplicate. $P$-values were calculated vs. control; ${ }^{* *} p<0.01 ;{ }^{* * *} p<0.001 ; * * * * 0<0.0001$.

First, we performed the MTT assay on LPS-stimulated RAW 264.7 cells, in order to assess the effect of increasing concentrations of the different extracts (from 1 to $50 \mu \mathrm{g} / \mathrm{mL}$ ) on cell viability. The results demonstrated that the treatment does not induce any significant decrease in cell growth (Figure 4B). Then, the murine macrophage-like cells were stimulated with LPS and treated with the extracts of Salvia officinalis leaves and flowers, at the same concentrations previously used. After $24 \mathrm{~h}$ of treatment, the Griess assay, performed on the culture medium, showed a marked reduction in $\mathrm{NO}$ using all the extracts tested, in a dose dependent manner (Figure 4A and Table 6).

Table 6. Inhibitory activity on the nitrites production.

\begin{tabular}{cc}
\hline Extract & IC $_{\mathbf{5 0}} \pm \mathbf{S D}(\mu \mathrm{g} / \mathrm{mL})$ \\
\hline S1 & $21.74 \pm 3.019$ \\
S2 & $31.92 \pm 3.695$ \\
S3 & $44.43 \pm 4.698$ \\
S4 & $25.02 \pm 3.901$ \\
S5 & $49.83 \pm 5.463$ \\
S6 & $22.95 \pm 3.846$ \\
S7 & $28.87 \pm 3.638$ \\
S8 & $58.83 \pm 6.890$ \\
\hline
\end{tabular}

Data are presented as IC50 values $(\mu \mathrm{g} / \mathrm{mL}) \pm$ standard deviation (SD) obtained by nonlinear regression analysis of three independent experiments. 
These outcomes are in agreement with the literature data, which has evidenced a wide range of pharmacological properties for $S$. officinalis, including the anti-inflammatory activity, due to their chemical constituents [40]. Accordingly, an interesting activity in the modulation of inflammatory processes can be ascribed to the extracts of Salvia officinalis leaves and flowers from Orsomarso and Civita. Furthermore, these results, together with the noticeable antioxidant activity elicited by S1-S8 extracts, laid the foundation for assessing a probable involvement of the NF- $\mathrm{kB}$ transcription factor in the mechanisms that underlie these effects. NF- $\kappa B$ acts as a pivot in inflammatory and oxidative stress response by inducing the inducible nitric oxide synthase expression which, in turn, catalyses the NO production $[19,25]$. The translocation of NF- $\kappa$ B from the cytosol to the nucleus determines the transcription of genes correlated with an increase in the oxidative and inflammatory state [19]. Thus, the nuclear translocation in LPS-stimulated murine macrophages was evaluated, after the S1-S8 exposure (Figure 5).
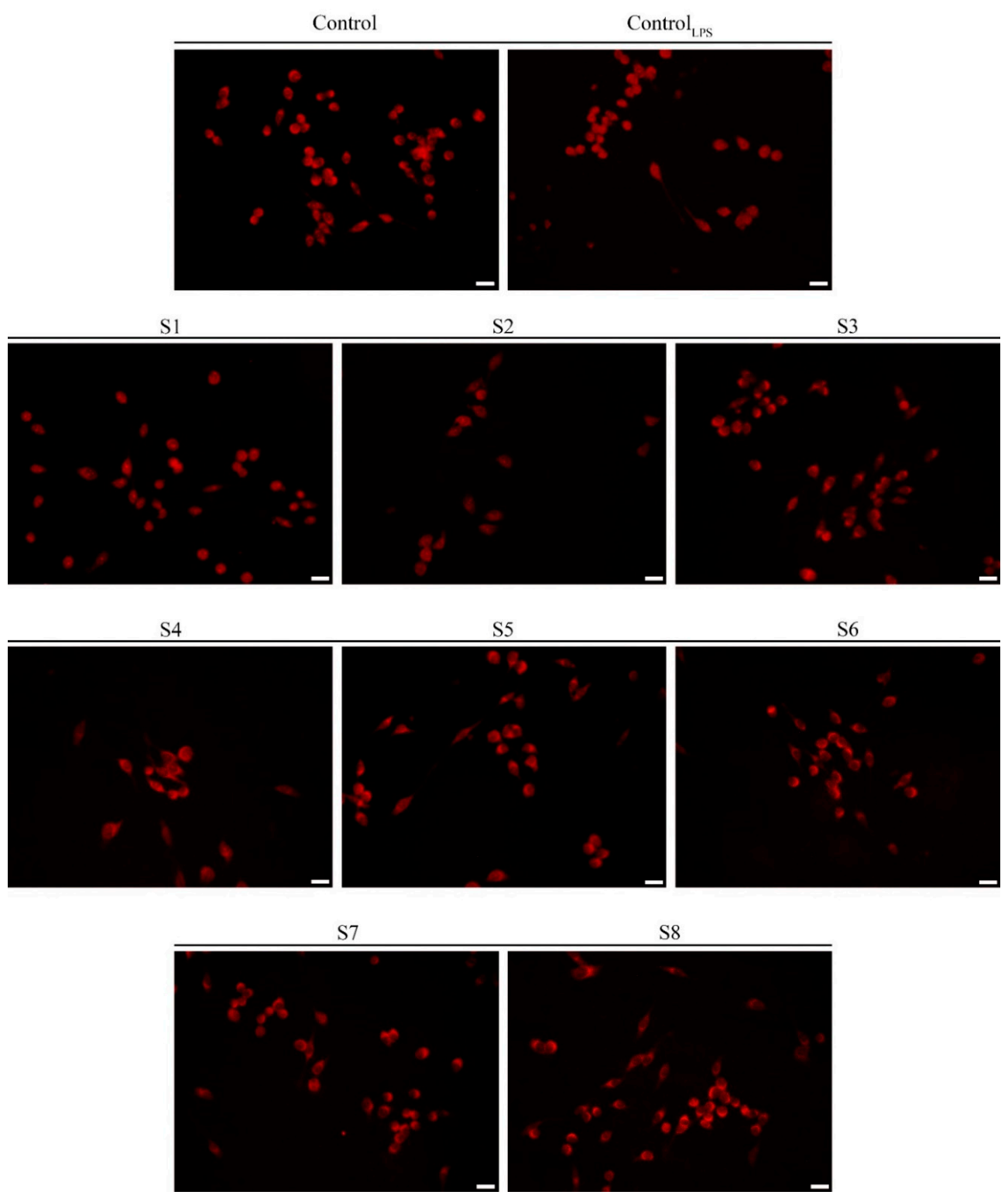

Figure 5. Salvia officinalis extracts interfere with the NF-kB nuclear translocation in RAW 264.7 cells. Immuno-fluorescent detection of NF- $\mathrm{KB}$ in cells treated with DMSO (control) or $1 \mu \mathrm{g} / \mathrm{mL} \mathrm{LPS}+\mathrm{DMSO}$ (control $\mathrm{LPS}_{\text {) }}$ or $1 \mu \mathrm{g} / \mathrm{mL} \mathrm{LPS}+\mathrm{S} 1-\mathrm{S} 8$ extracts (as indicated), at their $\mathrm{IC}_{50}$, for $1 \mathrm{~h}$. Scale bar: $50 \mu \mathrm{m}$. 
The results evidenced that murine macrophage-like cells not stimulated with LPS were characterized by fluorescence delimited in the cytosol, confirming the inactivation in the basal state of NF- $\mathrm{KB}$ signaling. By contrast, the fluorescence moved to the nucleus when the murine macrophage-like cells were exposed to LPS, underlining the translocation of NF- $\mathrm{KB}$ into the nucleus. As shown in Figure 5, the exposure of LPS-stimulated RAW 264.7 cells to Salvia officinalis extracts (S1-S8) evidenced a very similar condition to the basal one, in which the fluorescence was confined, to a great extent, into the cytosol.

\subsection{S. officinalis Extracts Reduce Pro-Inflammatory Cytokines}

The NF- $\mathrm{kB}$ pathway plays a key role in the maintenance of the inflammatory process as it promotes the transcription of various pro-inflammatory cytokines, an essential event for inflammatory stimulus propagation [41]. Based on the previous activity of extracts S1$\mathrm{S} 8$ to inhibit the NF- $\mathrm{KB}$ pathway, we performed the quantitative polymerase chain reaction (PCR) analysis in order to evaluate the expression of tumor necrosis factor alpha (TNF$\alpha$ ), interleukin-6 (IL-6), and interleukin-1 beta (IL-1 $\beta$ ), three important pro-inflammatory cytokines, at the transcript level. To this end, RAW 264.7 cells were stimulated with LPS and simultaneously exposed, for $6 \mathrm{~h}$, to $S$. officinalis extracts S1-S8, at the respective $\mathrm{IC}_{50}$ values. The results presented in Figure 6 confirmed that the extracts exhibited a remarkable anti-inflammatory potential, underlined by the reduction in the expression levels of the inflammatory cytokines. In particular, extracts S2, S3, and S4 were the most active as they elicited a clear decrease in the expression levels of the three pro-inflammatory cytokines evaluated.

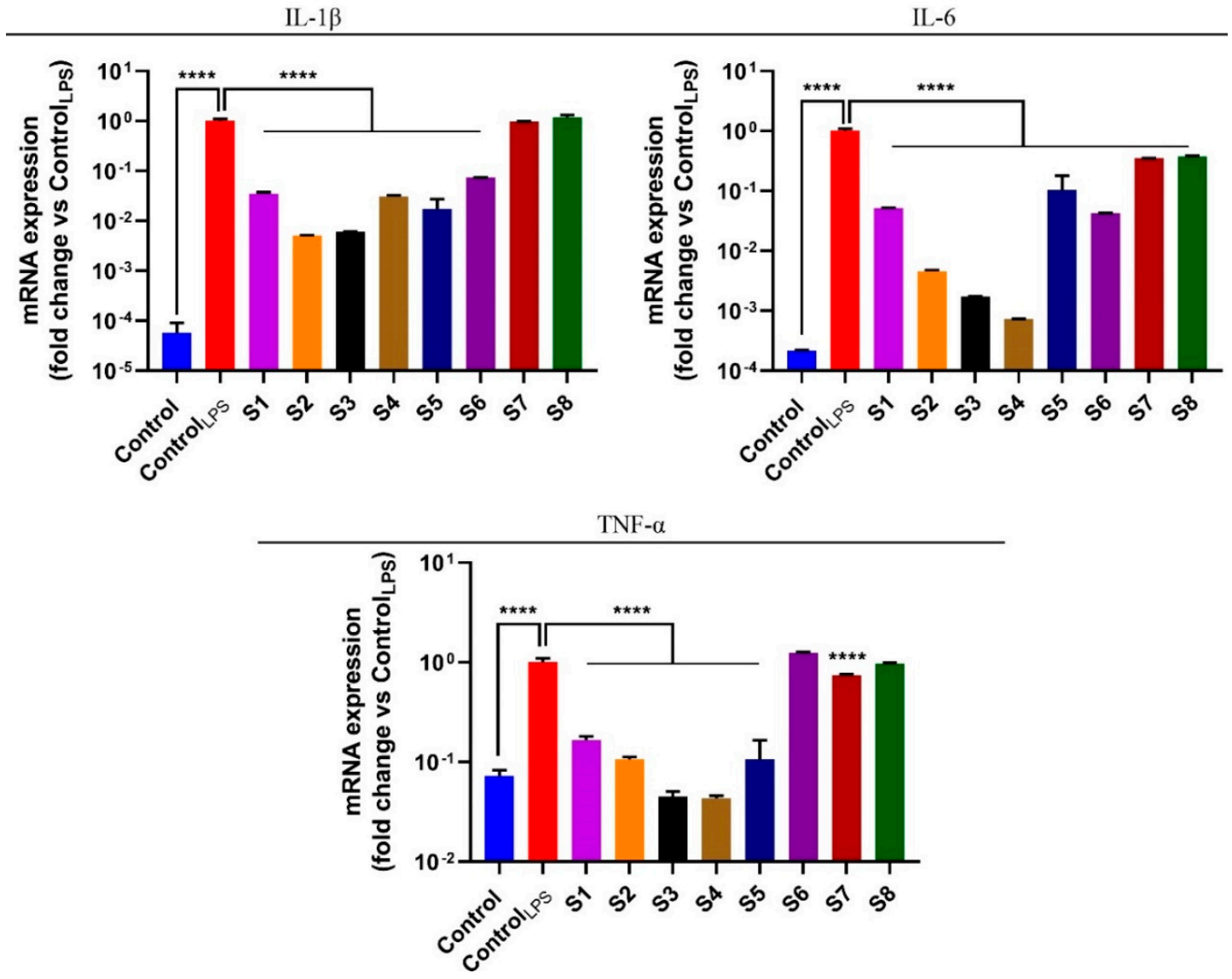

Figure 6. S1-S8 extracts and modulates regulate pro-inflammatory cytokines expression levels in LPS-stimulated RAW 264.7 cells. Effects are induced by the S. officinalis extracts treatment on mRNA levels of pro-inflammatory cytokines TNF- $\alpha$, IL-6, and IL-1 $\beta$ mRNA levels. RAW 264.7 cells were treated for $6 \mathrm{~h}$ with the vehicle (DMSO; control) or $1 \mu \mathrm{g} / \mathrm{mL} \mathrm{LPS}$ alone (control ${ }_{\text {LPS }}$ ) or with different sage extracts, at their respective $\mathrm{IC}_{50}$. Values are the mean $\pm \mathrm{SD}$ of three independent experiments, each one performed in triplicate. $P$-values were calculated against control ${ }_{\mathrm{LPS}} ;{ }^{* * * *} p<0.0001$. 


\subsection{S. officinalis Extracts Interfere with Inflammation Associated with Neoplastic Progression}

Inflammation is a physiological response triggered by the organism in order to overcome pathologic events including infection, or to repair tissue wounds. In this regard, it aims to defend the host organism [42]. However, dysregulated inflammatory mechanisms can lead to several diseases, including cancer [43].

In the past 20 years, inflammation has acquired an important role in cancer research as several neoplastic pathologies resulted from inflammatory processes transformed from physiological into pathological events, thus laying the foundation for the neoplastic process [43]. Several reports have demonstrated that some tumors are a direct consequence of severe inflammatory processes which, by subverting the tissue structure, potentially induce neoplasia. In recent years, there has been growing interest in the tumor microenvironment, as it is significantly involved in tumor progression. Literature data highlights the capacity of the tumor to release various factors such as cytokines and growth factors into the surrounding environment that are able to induce a systemic response, which in turn promotes tumor cell proliferation, survival, and migration [43]. Indeed, tumor cells liberate factors inducing new vessel formation in order to cope with the cancer tissue's high demand for nutrients [44].

The tumor microenvironment mostly contains fibroblasts and immune cells, including macrophages. Tumor-associated macrophages (TAMs) are M2-type macrophages surrounding malignant tumors whose presence is related to poor prognosis and survival [44]. It is known that breast cancer exhibits a large number of TAMs in the tumor microenvironment which interact and affect the surrounding cells that are involved in breast cancer progression and metastasis by several mechanisms. Therefore, therapies targeting these cells are under development and constitute a very attractive challenge for researchers [44]. Macrophages perform an action of considerable importance by phagocytizing and neutralizing pathogens foreign to our body. However, research by several teams has shown that the macrophages associated with a tumor are attracted to the tumor in response to the tumor's release of various cytokines. In tumor tissue, macrophages do not have the ability to phagocytize tumor cells but release further pro-inflammatory factors, thus feeding inflammation and promoting tumor progression. In this context, we wondered whether S. officinalis extracts would be able to interfere with the inflammatory activity induced by breast cancer cell-conditioned media. To this end, we evaluated the ability of MCF-7 and MDA-MB-231 breast cancer cells to release factors able to activate macrophages in the culture medium. For this purpose, cancer cells were treated with Salvia officinalis extracts for $24 \mathrm{~h}$. Then, cancer cell-conditioned media was collected, RAW 264.7 cells were exposed to it for $24 \mathrm{~h}$, and NO production was assessed using the Griess assay, after exposure. The results displayed that the treatment with all the S. officinalis extracts (except S5) significantly decreased NO production (Figure 7), highlighting the reduced ability of cancer cell-conditioned media to elicit macrophage activation.

This result highlights, for the first time, the important role of S. officinalis extracts in controlling the inflammation processes related to neoplastic progression. 


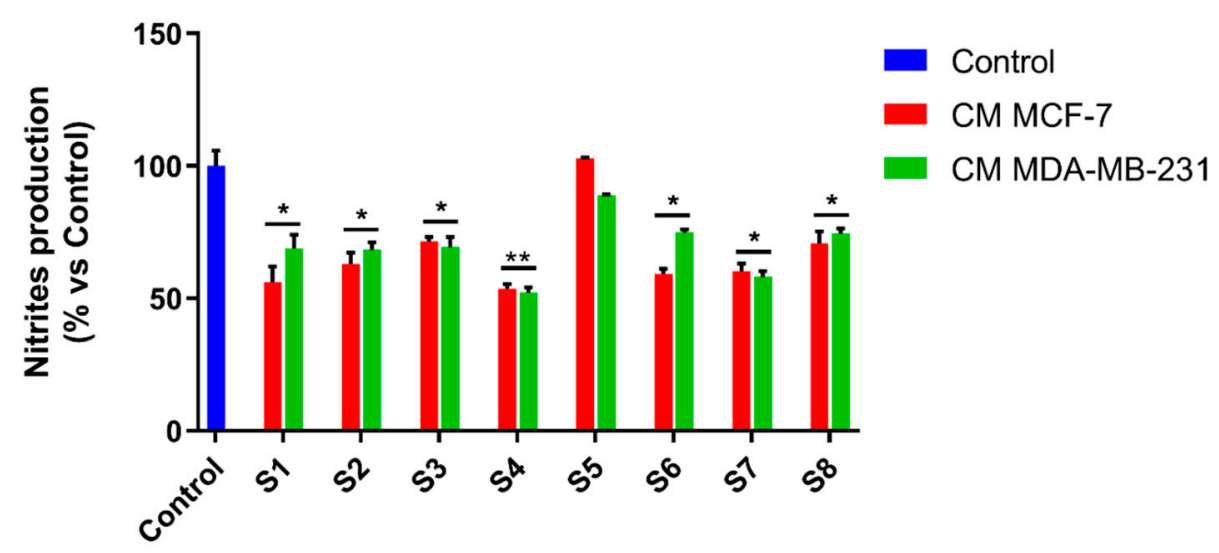

Figure 7. Salvia officinalis extracts decrease pro-inflammatory effects mediated by breast cancer cells conditioned media. Nitrites production was measured in RAW 264.7 cells after $24 \mathrm{~h}$ of treatment with conditioned media from MDA-MB-231 or MCF-7 cell lines (exposed before to $\mathrm{IC}_{50}$ values of S1-S8 extracts, for $24 \mathrm{~h}$ ). Values are the mean $\pm \mathrm{SD}$ of three independent experiments, each one performed in triplicate. $P$-values were calculated vs. control; ${ }^{*} p<0.05 ;{ }^{* *} p<0.01$.

\section{Conclusions}

The study of plants and phytocomplexes that can be extracted from them is a central topic in the research of recent years. In this report, Salvia officinalis and, in particular, the extracts obtained by maceration or ultrasound in methanol of the sage, harvested in two different parts of Italy, were evaluated. The extraction methods used, although different from each other, have allowed us to obtain very similar chemical profiles with some differences. In detail, the extracts obtained by maceration proved to be more rich in TPC and TFC. Regardless of the extraction method used, it was possible to observe that the flowers contain more rosmarinic acid unlike the leaves which contain more luteolin7-glucoside. The similar chemical profiles of Orsomarso and Civita sage extracts confer comparable activities in the four antioxidant assays. Indeed, the assays performed on the various extracts have shown a noticeable antioxidant effect (in ABTS and FRAP tests even better than the positive controls) regardless of the extraction method used, the part of the plant employed or the harvest area. These results confirm that Salvia officinalis is a rich source of antioxidant constituents. Moreover, our work aimed to evaluate if this high antioxidant potential results in beneficial effects on in vitro cellular models, focusing on the ability of sage extracts to modulate the oxidative stress induced by the inflammatory process. Indeed, since the close correlation between the inflammatory process and oxidative stress has been widely confirmed $[12,19,43]$, the research is aimed at the continuous identification of compounds and phytocomplexes able to induce the subversion of this close connection. Our findings of in vitro antioxidant tests have been confirmed in LPS-stimulated murine macrophages RAW 264.7 cells that responded to the inflammatory stimulus with a substantial ROS production. The ROS increase was remarkably diminished when the cells were exposed simultaneously to the sage extracts, conferring on them the ability to reduce the oxidative stress, a representative feature of the inflammatory process. This result highlights, for the first time, the effect of $S$. officinalis extracts in modulating oxidative stress induced by an inflammatory process.

Inflammation is a physiological process able to respond to physical insults such as wounds or pathogens infections $[43,45]$. The control of this path becomes crucial as its exponential activation can make the process chronic with consequent associated routes induction such as excessive oxidative stress, initiation, and neoplastic progression [45]. For this purpose, compounds acting on this pathway are interesting as they can manifest different biological potentials.

The different sage extracts investigated in this study displayed, in general, a similar chemical profile and, consequently, comparable activity in the cell and in the inflammatory 
path modulation. However, Orsomarso extracts were slightly more active, in terms of $\mathrm{IC}_{50}$, in reducing the nitric oxide, one of the key markers of the inflammatory process.

Anti-inflammatory and antioxidant activities, albeit similar to each other, showed that the extract obtained after maceration in methanol of the sage leaves collected in Orsomarso is most active in reducing NO and ROS production. This activity could be due to the high concentration of luteolin-7-glucoside and to the good concentration in the extract of rosmarinic acid and flavonoids, both molecules considered by the literature endowed with anti-inflammatory and antioxidant properties [12,46-48]. Furthermore, our outcomes proved that the promising anti-inflammatory activity, is related to a decrease of NF- $\mathrm{KB}$ translocation, one of the main players in the inflammatory process and to the reduction of the main pro-inflammatory cytokines. Finally, given the possible involvement of the inflammatory path in the neoplastic process, both as a consequence or as an initiating cause of the same, we demonstrated the ability of Salvia officinalis extracts to modulate the pro-inflammatory effects of the typical feature of tumor cells. This evidence established, for the first time, that Salvia officinalis extracts are endowed with interesting potentiality in reducing inflammatory processes related to neoplastic disease.

This work on the whole, confirms the knowledge on the antioxidant potential of Salvia officinalis and broadens it at the same time, by laying the foundation for the use of sage extracts as interesting inhibitors of the inflammatory path associated with the neoplastic process, very often a cause of both its progression and greater aggressiveness.

Author Contributions: Conceptualization, R.T., A.R.C., and M.S.C.; chemical analysis, R.T., C.B., A.D., and B.D.; biological investigation, M.B., L.F., M.S.C., and M.R.L.; writing-original draft preparation, M.B., L.F., A.R.C., R.T., and B.D.; writing-review and editing, R.T., M.R.L., G.L., and M.S.C.; supervision, R.T. and M.S.C. All authors have read and agreed to the published version of the manuscript.

Funding: L.F. is funded by PAC CALABRIA 2014-2020-Asse Prioritario 12, Azione B 10.5.12 CUP: H28D19000040006.

Acknowledgments: The authors would like to thank N.G. Passalacqua (Botany Department at the University of Calabria, Italy) for the botanical identification of our samples and Maria Rosaria Rose for the technical support. The graphical abstract was created with BioRender.com.

Conflicts of Interest: The authors declare no conflict of interest.

\section{References}

1. Walker, J.B.; Sytsma, K.J. Staminal evolution in the genus Salvia (Lamiaceae): Molecular phylogenetic evidence for multiple origins of the staminal lever. Ann. Bot. 2007, 100, 375-391. [CrossRef]

2. Jakovljević, M.; Jokić, S.; Molnar, M.; Jašić, M.; Babić, J.; Jukić, H.; Banjari, I. Bioactive profile of various Salvia officinalis L. preparations. Plants 2019, 8, 55. [CrossRef]

3. Tundis, R.; Loizzo, M.; Bonesi, M.; Leporini, M.; Menichini, F.; Passalacqua, N. A study of Salvia fruticosa Mill subsp. thomasii (Lacaita) Brullo, Guglielmo, Pavone \& Terrasi, an endemic Sage of Southern Italy. Plant Biosyst. 2018, 152, $130-141$.

4. Tundis, R.; Iacopetta, D.; Sinicropi, M.S.; Bonesi, M.; Leporini, M.; Passalacqua, N.G.; Ceramella, J.; Menichini, F.; Loizzo, M.R. Assessment of antioxidant, antitumor and pro-apoptotic effects of Salvia fruticosa Mill. subsp. thomasii (Lacaita) Brullo, Guglielmo, Pavone \& Terrasi (Lamiaceae). Food Chem. Toxicol. 2017, 106, 155-164. [PubMed]

5. Kolac, U.K.; Ustuner, M.C.; Tekin, N.; Ustuner, D.; Colak, E.; Entok, E. The anti-inflammatory and antioxidant effects of Salvia officinalis on lipopolysaccharide-induced inflammation in rats. J. Med. Food 2017, 20, 1193-1200. [CrossRef] [PubMed]

6. Zhao, J.; Lou, J.; Mou, Y.; Li, P.; Wu, J.; Zhou, L. Diterpenoid tanshinones and phenolic acids from cultured hairy roots of Salvia miltiorrhiza Bunge and their antimicrobial activities. Molecules 2011, 16, 2259-2267. [CrossRef]

7. Qnais, E.Y.; Abu-Dieyeh, M.; Abdulla, F.A.; Abdalla, S.S. The antinociceptive and anti-inflammatory effects of Salvia officinalis leaf aqueous and butanol extracts. Pharm. Biol. 2010, 48, 1149-1156. [CrossRef]

8. Baricevic, D.; Bartol, T.V. Pharmacology 11. The biological/pharmacological activity of the Salvia genus. Genus Salvia 2000, 143-184.

9. Fu, Z.; Wang, H.; Hu, X.; Sun, Z.; Han, C. The pharmacological properties of salvia essential oils. J. Appl. Pharm. Sci. 2013, 3, 122.

10. Mansourabadi, A.H.; Sadeghi, H.M.; Razavi, N.; Rezvani, E. Anti-inflammatory and analgesic properties of salvigenin, Salvia officinalis flavonoid extracted. Adv. Herb. Med. 2016, 2, 31-41. 
11. Osakabe, N.; Yasuda, A.; Natsume, M.; Yoshikawa, T. Rosmarinic acid inhibits epidermal inflammatory responses: Anticarcinogenic effect of Perilla frutescens extract in the murine two-stage skin model. Carcinogenesis 2004, 25, 549-557. [CrossRef] [PubMed]

12. Brindisi, M.; Bouzidi, C.; Frattaruolo, L.; Loizzo, M.R.; Tundis, R.; Dugay, A.; Deguin, B.; Cappello, A.R.; Cappello, M.S. chemical profile, antioxidant, anti-inflammatory, and anti-cancer effects of Italian Salvia rosmarinus Spenn. methanol leaves Extracts. Antioxidants 2020, 9, 826. [CrossRef]

13. Bayala, B.; Bassole, I.H.N.; Gnoula, C.; Nebie, R.; Yonli, A.; Morel, L.; Figueredo, G.; Nikiema, J.-B.; Lobaccaro, J.-M.A.; Simpore, J. Chemical composition, antioxidant, anti-inflammatory and anti-proliferative activities of essential oils of plants from Burkina Faso. PLoS ONE 2014, 9, e92122. [CrossRef] [PubMed]

14. Reuter, S.; Gupta, S.C.; Chaturvedi, M.M.; Aggarwal, B.B. Oxidative stress, inflammation, and cancer: How are they linked? Free Radic. Biol. Med. 2010, 49, 1603-1616. [CrossRef]

15. Tenuta, M.C.; Deguin, B.; Loizzo, M.R.; Dugay, A.; Acquaviva, R.; Malfa, G.A.; Bonesi, M.; Bouzidi, C.; Tundis, R. Contribution of flavonoids and iridoids to the hypoglycaemic, antioxidant, and nitric oxide (NO) inhibitory activities of Arbutus unedo L. Antioxidants 2020, 9, 184. [CrossRef]

16. Lehbili, M.; Alabdul Magid, A.; Kabouche, A.; Voutquenne-Nazabadioko, L.; Abedini, A.; Morjani, H.; Gangloff, S.C.; Kabouche, Z. Antibacterial, antioxidant and cytotoxic activities of triterpenes and flavonoids from the aerial parts of Salvia barrelieri Etl. Nat. Prod. Res. 2018, 32, 2683-2691. [CrossRef] [PubMed]

17. Koutsoulas, A.; Čarnecká, M.; Slanina, J.; Tóth, J.; Slaninová, I. Characterization of phenolic compounds and antiproliferative effects of Salvia pomifera and Salvia fruticosa extracts. Molecules 2019, 24, 2921. [CrossRef]

18. Brindisi, M.; Fiorillo, M.; Frattaruolo, L.; Sotgia, F.; Lisanti, M.P.; Cappello, A.R. Cholesterol and mevalonate: Two metabolites involved in breast cancer progression and drug resistance through the ERRalpha pathway. Cells 2020, 9, 1819. [CrossRef] [PubMed]

19. Frattaruolo, L.; Carullo, G.; Brindisi, M.; Mazzotta, S.; Bellissimo, L.; Rago, V.; Curcio, R.; Dolce, V.; Aiello, F.; Cappello, A.R. Antioxidant and anti-inflammatory activities of flavanones from Glycyrrhiza glabra L. (licorice) leaf phytocomplexes: Identification of licoflavanone as a modulator of NF-kB/MAPK pathway. Antioxidants 2019, 8, 186. [CrossRef]

20. Fiorillo, M.; Tóth, F.; Brindisi, M.; Sotgia, F.; Lisanti, M.P. Deferiprone (DFP) targets cancer stem cell (CSC) propagation by inhibiting mitochondrial metabolism and inducing ROS production. Cells 2020, 9, 1529. [CrossRef] [PubMed]

21. Perri, F.; Frattaruolo, L.; Haworth, I.; Brindisi, M.; El-magboub, A.; Ferrario, A.; Gomer, C.; Aiello, F.; Adams, J.D. Naturally occurring sesquiterpene lactones and their semi-synthetic derivatives modulate PGE2 levels by decreasing COX2 activity and expression. Heliyon 2019, 5, e01366. [CrossRef]

22. Bonesi, M.; Brindisi, M.; Armentano, B.; Curcio, R.; Sicari, V.; Loizzo, M.R.; Cappello, M.S.; Bedini, G.; Peruzzi, L.; Tundis, R. Exploring the anti-proliferative, pro-apoptotic, and antioxidant properties of Santolina corsica Jord. \& Fourr. (Asteraceae). Biomed. Pharmacother. 2018, 107, 967-978.

23. Armentano, B.; Curcio, R.; Brindisi, M.; Mancuso, R.; Rago, V.; Ziccarelli, I.; Frattaruolo, L.; Fiorillo, M.; Dolce, V.; Gabriele, B. 5-(Carbamoylmethylene)-oxazolidin-2-ones as a promising class of heterocycles inducing apoptosis triggered by increased ros levels and mitochondrial dysfunction in breast and cervical cancer. Biomedicines 2020, 8, 35. [CrossRef]

24. Casaburi, I.; Avena, P.; De Luca, A.; Chimento, A.; Sirianni, R.; Malivindi, R.; Rago, V.; Fiorillo, M.; Domanico, F.; Campana, C.; et al. Estrogen related receptor alpha (ERRalpha) a promising target for the therapy of adrenocortical carcinoma (ACC). Oncotarget 2015, 6, 25135-25148. [CrossRef]

25. Mazzotta, S.; Frattaruolo, L.; Brindisi, M.; Ulivieri, C.; Vanni, F.; Brizzi, A.; Carullo, G.; Cappello, A.R.; Aiello, F. 3-Amino-alkylated indoles: Unexplored green products acting as anti-inflammatory agents. Future Med. Chem. 2020, 12, 5-17. [CrossRef] [PubMed]

26. Sun, T.; Tanumihardjo, S. An integrated approach to evaluate food antioxidant capacity. J. Food Sci. 2007, 72, R159-R165. [CrossRef] [PubMed]

27. Jin, Q.; Hu, X.; Deng, Y.; Hou, J.; Lei, M.; Ji, H.; Zhou, J.; Qu, H.; Wu, W.; Guo, D. Four New Depsides Isolated from Salvia miltiorrhiza and their significant nerve-protective activities. Molecules 2018, 23, 3274. [CrossRef]

28. Kasimu, R.; Tanaka, K.; Tezuka, Y.; Gong, Z.-N.; Li, J.-X.; Basnet, P.; Namba, T.; Kadota, S. Comparative study of seventeen Salvia plants: Aldose reductase inhibitory activity of water and $\mathrm{MeOH}$ extracts and liquid chromatography-mass spectrometry (LC-MS) analysis of water extracts. Chem. Pharm. Bull. 1998, 46, 500-504. [CrossRef]

29. Moharram, F.A.E.; Marzouk, M.S.; El-Shenawy, S.M.; Gaara, A.H.; El Kady, W.M. Polyphenolic profile and biological activity of Salvia splendens leaves. J. Pharm. Pharmacol. 2012, 64, 1678-1687. [CrossRef]

30. Lu, Y.; Foo, L.Y. Flavonoid and phenolic glycosides from Salvia officinalis. Phytochemistry 2000, 55, 263-267. [CrossRef]

31. Nadeem, M.; Imran, M.; Aslam Gondal, T.; Imran, A.; Shahbaz, M.; Muhammad Amir, R.; Wasim Sajid, M.; Batool Qaisrani, T.; Atif, M.; Hussain, G. Therapeutic potential of rosmarinic acid: A comprehensive review. Appl. Sci. 2019, 9, 3139. [CrossRef]

32. Cuvelier, M.E.; Berset, C.; Richard, H. Antioxidant constituents in sage (Salvia officinalis). J. Agric. Food Chem. 1994, 42, 665-669. [CrossRef]

33. Loussouarn, M.; Krieger-Liszkay, A.; Svilar, L.; Bily, A.; Birtić, S.; Havaux, M. Carnosic acid and carnosol, two major antioxidants of rosemary, act through different mechanisms. Plant Physiol. 2017, 175, 1381-1394. [CrossRef]

34. Sosa, V.; Moliné, T.; Somoza, R.; Paciucci, R.; Kondoh, H.; LLeonart, M.E. Oxidative stress and cancer: An overview. Ageing Res. Rev. 2013, 12, 376-390. [CrossRef] [PubMed] 
35. Veskoukis, A.S.; Tsatsakis, A.M.; Kouretas, D. Dietary oxidative stress and antioxidant defense with an emphasis on plant extract administration. Cell Stress Chaperones 2012, 17, 11-21. [CrossRef]

36. Sindhi, V.; Gupta, V.; Sharma, K.; Bhatnagar, S.; Kumari, R.; Dhaka, N. Potential applications of antioxidants-A review. J. Pharm. Res. 2013, 7, 828-835. [CrossRef]

37. Yurtseven, S.; Cetin, M.; Şengül, T.; Sögüt, B. Effect of sage extract (Salvia officinalis) on growth performance, blood parameters, oxidative stress and DNA damage in partridges. S. Afr. J. Anim. Sci. 2008, 38, 145-152.

38. Castillo-Morales, R.M.; Otero, A.L.C.; Mendez-Sanchez, S.C.; Da Silva, M.A.N.; Stashenko, E.E.; Duque, J.E. Mitochondrial affectation, DNA damage and AChE inhibition induced by Salvia officinalis essential oil on Aedes aegypti larvae. Comp. Biochem. Physiol. C Toxicol. Pharmacol. 2019, 221, 29-37. [CrossRef] [PubMed]

39. Crascì, L.; Lauro, M.R.; Puglisi, G.; Panico, A. Natural antioxidant polyphenols on inflammation management: Anti-glycation activity vs metalloproteinases inhibition. Crit. Rev. Food Sci. Nutr. 2018, 58, 893-904. [CrossRef] [PubMed]

40. Ghorbani, A.; Esmaeilizadeh, M. Pharmacological properties of Salvia officinalis and its components. J. Tradit. Complement. Med. 2017, 7, 433-440. [CrossRef]

41. Seo, E.-J.; Fischer, N.; Efferth, T. Phytochemicals as inhibitors of NF-kB for treatment of Alzheimer's disease. Pharmacol. Res. 2018, 129, 262-273. [CrossRef]

42. Sousa, L.P.; Alessandri, A.L.; Pinho, V.; Teixeira, M.M. Pharmacological strategies to resolve acute inflammation. Curr. Opin. Pharmacol. 2013, 13, 625-631. [CrossRef] [PubMed]

43. Coussens, L.M.; Werb, Z. Inflammation and cancer. Nature 2002, 420, 860-867. [CrossRef] [PubMed]

44. Lee, S.; Lee, E.; Ko, E.; Ham, M.; Lee, H.M.; Kim, E.-S.; Koh, M.; Lim, H.K.; Jung, J.; Park, S.Y. Tumor-associated macrophages secrete CCL2 and induce the invasive phenotype of human breast epithelial cells through upregulation of ERO1- $\alpha$ and MMP-9. Cancer Lett. 2018, 437, 25-34. [CrossRef] [PubMed]

45. Strowig, T.; Henao-Mejia, J.; Elinav, E.; Flavell, R. Inflammasomes in health and disease. Nature 2012, 481, 278-286. [CrossRef]

46. Hu, C.; Kitts, D.D. Luteolin and luteolin-7-O-glucoside from dandelion flower suppress iNOS and COX-2 in RAW264.7 cells. Mol. Cell Biochem. 2004, 265, 107-113. [CrossRef] [PubMed]

47. Burda, S.; Oleszek, W. Antioxidant and antiradical activities of flavonoids. J. Agric. Food Chem. 2001, 49, 2774-2779. [CrossRef] [PubMed]

48. Garcia-Lafuente, A.; Guillamon, E.; Villares, A.; Rostagno, M.A.; Martinez, J.A. Flavonoids as anti-inflammatory agents: Implications in cancer and cardiovascular disease. Inflamm. Res. 2009, 58, 537-552. [CrossRef] 